\title{
BIOLOGICAL FEATURES OF BLOOD LYMPHOCYTES OF THE PRIMARY PA- TIENTS WITH ENDOMETRIAL CANCER
}

\section{Emiliia Domina, Olha Hrinchenko}

The aim: to examine the radiosensitivity of chromosomes of T-lymphocytes in the blood of primary patients with endometrial cancer depending on the radiation dose. It was expected that the investigations would reveal a cytogenetic parameter as a predictor of radiosensitivity in non-malignant cells of patients exposed to curative irradiation.

Materials and methods. Blood samples from 20 primary patients and 30 conditionally healthy donors were examined. Peripheral blood T-lymphocytes culture test system with metaphase chromosome aberration analysis was used. X-ray test-irradiation was performed at G0-stage of the cell cycle in the dose range of 0.5-3.0 Gy.

Results. It was shown that the spontaneous level of chromosome aberrations in lymphocytes of primary patients before anti-tumour therapy is 7,82 $\pm 0,33$ aberrations/100 metaphases. This is more than 2-fold higher than the upper limit of average population index and approximately 6-fold higher than the data of own control. In our study during X-ray irradiation of cells cultures of patients, it was found for the first time that the total frequency of radiation-induced chromosome aberrations obeys the classical linear quadratic dose dependence with a predominance of linear component values; the frequency of radiation markers - also linear quadratic dose dependence, but with a predominance of quadratic component.

Conclusions. High specificity of T-lymphocyte chromosomes to exposure to ionizing radiation as well as strict dependence of chromosome aberration yield on exposure dose justify their use as predictors of radiosensitivity of healthy cells from the tumour environment. The revealed dependences of induction of chromosomal damage in T-lymphocytes of patients with endometrial cancer prove the need for a personalized approach to plan the course of radiation therapy

Keywords: endometrial cancer, radiation therapy, blood T-lymphocytes, chromosomal aberrations, dose dependence, predictors of radiosensitivity

How to Cite:

Domina, E., Hrinchenko, O. (2021). Biological features of blood lymphocytes of the primary patients with endometrial cancer. ScienceRise: Biological Science, 1 (26), 4-9. doi: http://doi.org/10.15587/2519-8025.2021.227335

(C) The Author(s) 2021

This is an open access article under the CC BY license (http://creativecommons.org/licenses/by/4.0).

\section{Introduction}

The relevance of radiobiological research is explained by the growth of cancer morbidity, including endometrial cancer (EC) among the female population of Ukraine. According to the National Cancer Registry (2018-2019), EC ranks third in the structure of cancer morbidity among the female population of Ukraine (9.6\%). In 2018, the incidence rate per 100 thousand female population was 36.1 [1]. The majority of patients are prescribed a combined treatment including surgical method and post-surgery radiation therapy. Therefore, the search for new ways to predict the effectiveness of radiation treatment in these patients is urgent.

\section{Literature review}

The area of constant practical application of radiobiological knowledge is radiation therapy. It is known that the efficacy of radiation therapy is determined by the state of balance between lesions of the tumour and healthy tissue. Therefore, the issues of reducing the degree of radiation damage to the latter have always been in the focus of attention of radiation oncologists. Radiation therapy does not achieve complete regression of tumours in the majority of cancer patients. The dose required for a cure cannot be administered due to the danger of exceeding the tolerance of normal tissues [2]. The tumour locus is characterized by the lack of clear boundaries, which necessitates the increase of the irradiation field. This leads, along with the tumour destruction, to the similar changes in the healthy tissues around the tumour. Previously, this dependence forced radiation therapists, when choosing a radiation dose on an empirical basis, to balance between the probability of recurrence and the danger of irreversible radiation damage to normal tissues. In modern conditions due to the introduction of new technologies in radiation oncology and conformal strategy of therapeutic irradiation, it is often possible to reduce the damage of healthy tissues. However, the risk of adverse radiation reactions from normal tissues remains high in some cases [3, 4].

Among the early effects of therapeutic irradiation that form in rapidly proliferating cells, their hyperplasia plays a key role. Radiation reactions from the epidermis, especially at the entrance of the ionizing radiation (IR) beam, limit the use of high doses in radiology. After radiation therapy, late complications can develop, which are irreversible and progressive. Most often they are represented by atrophy, telangiectasia, necrosis. Fibroblasts are also involved in pathogenesis of late radiation effects, synthesis of collagen and its deposition in tissues in- 
crease. This leads to the dysfunction of corresponding organs [5]. These reactions are under the control of growth factor- $\beta$ (TGF- $\beta)[6,7]$.

The intestine is a critical organ in radiation therapy because of the high radiosensitivity of the mucosal epithelium and the threat of bacterial sepsis. In addition, radiation therapy of brain tumours can cause adverse reactions of the thyroid gland and pituitary gland. The distant radiation consequences of therapeutic irradiation include secondary cancer of radiation aetiology $[8,9]$. One of the main problems in achieving the therapeutic effect remains severe complications during irradiation of pelvic organs, i.e. radiation proctitis and cystitis [3]. This applies to oncologic patients, including EC during brachytherapy.

At the Institute of Experimental Pathology, Oncology and Radiobiology of the National Academy of Sciences of Ukraine a model system is being developed to determine the predictors of radiosensitivity of cancer patients in order to reduce the frequency and severity of post-radiation complications from healthy tissues and organs from the tumour environment. The grounds for such studies are data on molecular, chromosomal and other abnormalities in healthy cells of primary cancer patients [10-12]. The observed changes can affect the functional state of these cells, including their radiosensitivity. Additional radiation-induced damage in healthy cells as a result of therapeutic irradiation will contribute to a high risk of radiation complications.

Studies of recent years do not allow to clearly identify a single biological trait that would allow to predict with a high probability the efficacy of radiation therapy [13]. When irradiating indicator (highly radiosensitive) cells, such as blood lymphocytes, a cascade of processes is induced, including activation of DNA repair processes and cell cycle checkpoints control systems, chromatin reconstruction, apoptosis amplification. It is important to state that cellular DNA repair systems ensure tumour radioresistance, thus reducing the efficacy of therapeutic irradiation [14]. It is necessary to take into consideration the opinion of some researchers that repair processes in irradiated tumour cells can occur more effectively in comparison to normal cells because they are characterized by increased expression of enzymes of repair processes [15]. Dozens, hundreds of genes are involved in these processes. In general, changes in their expression usually lead to increased radiosensitivity [16]. The success of radiation treatment depends on many factors: the magnitude of dose and mode of irradiation, the target volume, oxygen concentration in the irradiation zone, radiosensitivity of the tumour, individual radiosensitivity of the patient, proliferative potential of tissues, concomitant diseases, the severity of early and late radiation complications, and other factors. A change in any of these factors can lead to a modification of the radiation response not only from the tumour cells, but also from the healthy cells in its surroundings.

The above-mentioned explain the need for further development of convincing biological assumptions for the prognosis of distant radiation complications on the part of healthy tissues that fall within the irradiation field. Such tissues include the pool of circulating peripheral blood, includ- ing highly radiosensitive T-lymphocytes. They carry out immunological supervision over the antigenic constancy of the organism. Moreover, lymphocytes in constant contact with tumour cells due to "bystander effect" can acquire their properties, including sensitivity to radiation [17]. In addition, in case of contradictions between physical dosimetry data and clinical presentation of distant effects of irradiation, the method of chromosome aberration analysis in blood $\mathrm{T}$ lymphocytes is used. It is one of the most adequate ways to estimate the absorbed dose of IR [18].

The following questions thus arise: what biological changes are formed in normal cells of patients with a particular tumour localization, associated with the effectiveness of radiation treatment; and could peripheral blood T-lymphocytes (PBL) serve as predictors of radiosensitivity of non-malignant cells?

\section{The aim of the research}

The aim of the research is to examine the radiosensitivity of chromosomes of T-lymphocytes in the blood of primary EC patients depending on the radiation dose.

To accomplish the aim, the following tasks have been set:

1. To investigate the spontaneous level of chromosome aberrations in the blood T-lymphocytes of primary EC patients. Results should be compared with those of healthy donors indicators.

2. To study the frequency and spectrum of radiation-induced chromosome aberrations in the test irradiation of the culture of T-lymphocytes of EC patients in a wide range of doses.

3. To determine the character of dose curves obtained for total chromosome aberration rate and radiation markers using linear-quadratic regression model.

\section{Materials and methods}

Blood samples from 20 primary EC patients (study group) and 30 healthy donors (comparison group) were examined. Informed consent was obtained from all patients and donors for additional laboratory examination and use of their biological materials for research purposes. Venous blood was placed in sterile $6 \mathrm{ml}$ vacutainer tubes with the anticoagulant Li-heparin and stored at $3-5{ }^{\circ} \mathrm{C}$. PBL culture test system with metaphase chromosome aberration analysis was used. PBL cultured, cytogenetic preparations were prepared, and metaphase analysis of uniformly stained chromosomes was performed according to the international standard protocol [19] with some modifications [20]. Phytohemagglutinin (form M, "Gibco Introgen", USA), which stimulates T-lymphocyte mitoses, was used as a mitogen. To accumulate the metaphases 3 hours before the end of incubation, colcemid ("Gibco KaryoMAX Colcemid Solution in PBS"s, USA) was added.

Metaphase analysis of chromosome aberrations was performed in the first mitosis, i.e. cells were fixed for $50 \mathrm{~h}$ of cultivation. Chromosomal and chromatid type aberrations, fragments, and exchanges were analyzed. Gaps were not counted.

$\mathrm{X}$-ray test-irradiation of PBL cultures was performed at $\mathrm{G}_{0}$-stage of the cell cycle in the dose range of 0.5-3.0 Gy. 
Statistical processing of the results was performed using "Statistika" package. Mathematical analysis of changes in cytogenetic parameters depending on exposure dose was performed based on linear-quadratic regression model: $Y=\alpha D+\beta D^{2}+c$, where $D$ states for exposure dose, $\alpha$ states for linear term of the equation, $\beta$ states for quadratic term of the equation, $c$ states for control level. Model parameters were calculated using the least square method [21].

\section{Research results}

According to the literature and our own studies, the rate of spontaneous chromosome aberrations is known to vary in the range of 0-3 aberrations/100 metaphases. But the value of this index can vary significantly under the influence of external and internal factors, including patients' clinical data under study. The results of our studies have shown that the spontaneous level of chromosome aberrations in PBL of primary EC patients before anti-tumour therapy is $7.82 \pm 0.33$ aberrations $/ 100$ metaphases. This is more than 2-fold higher than the upper limit of average population index and approximately 6-fold higher than the data of own control (Tables 1,2). Interindividual variations of the index are in the range from 5 to 10 aberra- tions/100 metaphases. Chromatid type aberrations dominate in the spectrum of registered chromosome rearrangements. Deletions account for $66 \%$ of their total number. Furthermore, there are also exchanges of chromatid and chromosomal types in the spectrum of aberrations.

Thus, the total frequency of chromosome aberrations in the patients' blood T-lymphocytes the start of radiation therapy exceeds the value of the average population index due mainly to chromatid type aberrations. This may indicate the formation of genetic instability in nonmalignant cells of patients due to carcinogenesis and low efficiency of repair processes in normal cells from the tumour environment. According to modern concepts, the radiosensitivity of cells and the organism as a whole is determined by its reparative potential, which is closely related to the immune system. In our study the mitotic index of PBL of patients is $50.8 \pm 4.6 \%$, which is $20 \%$ lower than that of healthy donors (Tables 1,2 ).

This indicates an initial decrease in the immunocompetence of patients' blood T-lymphocytes, i.e. before the start of radiation therapy. Thus, one of the oncology paradigms is confirmed: the disorder of genome stability and balance is an important part of carcinogenesis and occurs against the background of immunosuppression.

Table 1

Statistical data of cytogenetic parameters of blood lymphocytes of primary endometrial cancer patients*

\begin{tabular}{|c|c|c|c|}
\hline Cytogenetic indicators / 100 cells & Mean values & Minimum & Maximum \\
\hline Aberrant metaphases, $\%$ & $7.59 \pm 0.32$ & 5 & 10 \\
\hline Total frequency of chromosome aberrations & $7.82 \pm 0.33$ & 5 & 10 \\
\hline Frequency of aberrations per 1 cell & $1.03 \pm 0.02$ & 1 & 1,3 \\
\hline Frequency of aberrations of chromatid type & $5.06 \pm 0.51$ & 1 & 8 \\
\hline Chromatid fragments & $3.47 \pm 0.35$ & 0 & 6 \\
\hline Isodeletions & $0.12 \pm 0.08$ & 0 & 1 \\
\hline Chromatid exchanges & $1.47 \pm 0.24$ & 0 & 3 \\
\hline Frequency of chromosomal type aberrations & $2.77 \pm 0.47$ & 0 & 7 \\
\hline Paired fragments & $1.82 \pm 0.27$ & 0 & 4 \\
\hline Dicentric chromosomes & $0.12 \pm 0.08$ & 0 & 1 \\
\hline Ring chromosome & $0.18 \pm 0.10$ & 0 & 1 \\
\hline Acentric rings and interstitial deletions & $0.06 \pm 0.01$ & 0 & 1 \\
\hline Abnormal chromosome & $0.59 \pm 0.3$ & 0 & 4 \\
\hline Mitotic index, \%o & $50.8 \pm 4.6$ & 15 & 87 \\
\hline
\end{tabular}

Note: *-study group

Table 2

Statistical data of cytogenetic parameters of blood lymphocytes of conditionally healthy donors*

\begin{tabular}{|c|c|c|c|}
\hline Cytogenetic indicators / 100 cells & Mean values & Minimum & Maximum \\
\hline Aberrant metaphases, \% & $1.34 \pm 0.37$ & 0 & 3 \\
\hline Total frequency of chromosome aberrations & $1.34 \pm 0.37$ & 0 & 3 \\
\hline Frequency of aberrations per 1 cell & $0.8 \pm 0.1$ & 0 & 1 \\
\hline Frequency of aberrations of chromatid type & $0.67 \pm 0.24$ & 0 & 2 \\
\hline Chromatid fragments & $0.67 \pm 0.24$ & 0 & 2 \\
\hline Isodeletions & 0 & 0 & 0 \\
\hline Chromatid exchanges & 0 & 0 & 0 \\
\hline Frequency of chromosomal type aberrations & $0.67 \pm 0.24$ & 0 & 2 \\
\hline Paired fragments & $0.56 \pm 0.2$ & 0 & 2 \\
\hline Dicentric chromosomes & 0 & 0 & 0 \\
\hline Ring chromosome & 0 & 0 & 0 \\
\hline Acentric rings and interstitial deletions & $0.11 \pm 0.1$ & 0 & 1 \\
\hline Abnormal chromosome & 0 & 0 & 0 \\
\hline Mitotic index, \%o & $62 \pm 5.24$ & 45 & 89 \\
\hline
\end{tabular}

Note: *-comparison group 
A mandatory requirement for predictors of radiosensitivity is a strict quantitative relationship with the radiation dose.

To estimate the nature of the dose curves, we used a linear-quadratic model of cellular radiation damage, which includes a linear $\alpha$-member of the equation depending on the radiation dose and a quadratic $\beta$-member depending on the radiation dose squared. This model is based on the microdosimetric concepts that Köllerer and Rossi formulated in dual action theory. This means that the energy, which must be absorbed in the target to produce a biological effect, can result from either one or two hits. Therefore, the dose curves are approximated by the equation $Y=\alpha D+\beta D^{2}+c$, and the coefficients before $\mathrm{D}$ and $\mathrm{D}^{2}$ reflect the relative role of the two mechanisms [22].
In our study during X-ray irradiation of PBL cultures of EC patients in the range of 0.5-3.0 Gy, it was found for the first time that the total frequency of radiation-induced chromosome aberrations obeys the classical linear quadratic dose dependence with a predominance of linear component values $(\alpha=6.644)$; the frequency of radiation markers (dicentrics) - also linear quadratic dose dependence, but with a predominance of quadratic component $(\beta=1,308)$, Fig. 1 . The data obtained unequivocally indicate that T-lymphocytes in the blood of EC patients before the start of radiation therapy can serve as predictors of radiosensitivity of cells from the tumour environment that are entering the therapeutic irradiation zone.

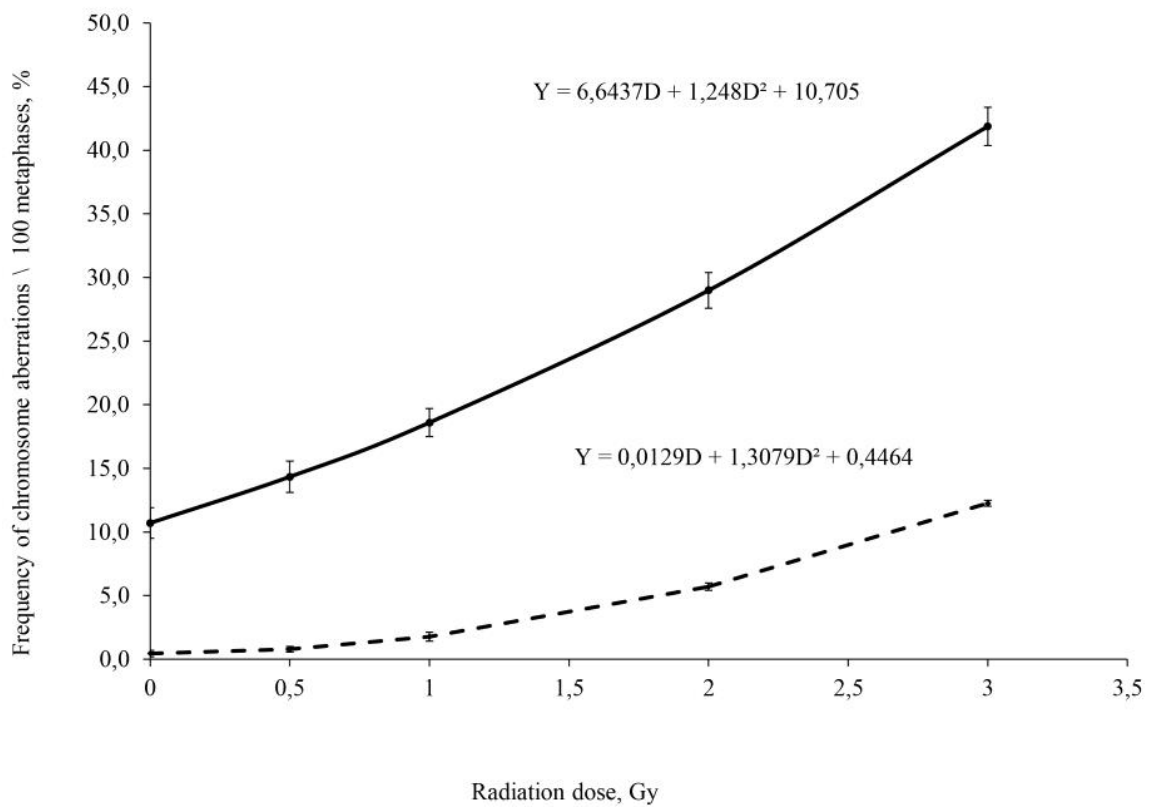

Fig. 1. Total frequency of chromosome aberrations (solid line) and radiation markers - dicentric chromosomes (dotted line) in PBL of EC patients depending on the dose of test irradiation

The revealed increased level of spontaneous aberrations of chromosomes in the PBL of patients before the start of radiation therapy in $25 \%$ of cases is associated with the development of late complications (rectitis, cystitis). This concerned patients with a burdened diagnosis (diabetes mellitus, work with sources of IR). The clinical significance of these observations requires further confirmation.

\section{Discussion of research results}

Recently in oncology much attention is given to the "tumour and organism" problem, including changes in healthy cells from the tumour microenvironment. The question regarding the manifestation of genomic instability in these cells and its potential relation to the efficacy of radiation therapy in cancer patients remains understudied. The cytogenetic examination of cancer patients before radiation therapy and assessment of the pattern of dose calibration curves in the most radiosensitive cells allow one to quantitatively assess the formation of radiation-induced chromosome aberrations (genome instability) in cells of the tumour microenvironment. These include cells of the hemato-immune system - T-lymphocytes of the circulat- ing blood pool, which are highly radiosensitive and are in constant contact with tumour tissue. A number of studies have examined patients with various tumour localisations using cytogenetic methods (23-25 et al., 2009). Often, the number of patients examined was insufficient for definitive conclusions. For example, in [17] it was found that the frequency of cells with chromosome aberrations in lymphocytes of prostate cancer patients, as well as the number of aberrations per cell do not differ from those in the group of healthy donors. However, the sample in this study was too small to draw conclusions (6 patients). Our work is based on cytogenetic examination of $20 \mathrm{EC}$ patients before radiation therapy and 30 observations with in vitro dose curves $(0 ; 0.5 ; 1.0 ; 2.0$ and 3.0 Gy of x-ray radiation).

The work highlighted an increased level of chromosome aberrations in T-lymphocytes of blood of EC patients, as well as individual variability of this index (Table 2). The results obtained provide evidence of a significant influence of individual characteristics of EC patients on the efficiency of repair processes and, consequently, on radiosensitivity of non-malignant cells. Earlier we pointed out that strict dose-effect relation is an obligatory requirement for predictors of radiosensitivity of hu- 
man cells. In our study it was shown that T-lymphocytes of EC patients are characterized, first, by specificity to radiation exposure (induction of radiation markers); second, the level of radiation-induced chromosome aberrations obeys the linear quadratic dose-dependence. This allows using cytogenetic indices of T-lymphocytes from EC patients as predictors of radiosensitivity of normal cells from the tumour environment and as prognostic criteria for late effects of therapeutic irradiation. It is possible that according to our developed hypothesis [26, 27], the radiosensitivity of the organism can be influenced (increased) by a COVID-19 infection, which should be reflected in the oncogynecological patient's medical history.

In order to improve the efficacy of radiation therapy of cancer patients, we consider it advisable to continue the search for predictors of radiosensitivity of cells from the tumour environment at molecular, biochemical and biophysical levels, which will provide a comprehensive approach to the solution of the problem.

The continuation of the above-mentioned studies is one of the highly promising directions in radiation oncology. A further search for the radiosensitivity predictors of healthy tissues and organs of cancer patients adjacent to the irradiated target tumour will help to prevent the post-irradiation complications.

\section{Conclusions}

Cytogenetic differences between T-lymphocytes of primary EC patients and healthy donors consist in the increased frequency of spontaneous chromosome aberrations (7.82 \pm 0.33 aberrations $/ 100$ metaphases) due to the deletions and exchanges of chromatid and chromosome types.

The study established, for the first time, that the total frequency of radiation-induced chromosome aberrations in blood T-lymphocytes of EC patients is subject to a linear quadratic dose-dependence with prevalence of linear component, and the frequency of radiation markers (dicentrics) - with prevalence of quadratic component. High specificity of T-lymphocyte chromosomes to exposure to ionizing radiation as well as strict dependence of chromosome aberration yield on exposure dose justify their use as predictors of radiosensitivity of healthy cells from the tumour environment.

The results of the study can be recommended for the prediction of long-term post-radiation complications in oncogynecological patients.

\section{Conflicts of interest.}

The authors declare that they have no conflicts of interest.

\section{References}

1. Fedorenko, Z. P., Hulak, L. O., Mykhailovych, Yu. Y., Horokh, Ye. L., Ryzhov, A. Yu., Sumkina, O. V., Kutsenko, L. B.; Kolesnik, O. O. (Ed.) (2020). Rak v Ukraini, 2018-2019 rr. Zakhvoriuvanist, smertnist, pokaznyky diialnosti onkolohichnoi sluzhby: Biuleten Natsionalnoho kantser-reiestru No. 21 Natsionalnoho instytutu raku Ukrainy. Kropyvnytskyi: POLIUM, 148.

2. Joiner, M., Kogel, A. (2013). Basic clinical radiobiology. London: Hodder Arnold an Haccette UK Company, 375. doi: http://doi.org/10.1201/b15450

3. Domina, E. A., Philchenkov, A., Dubrovska, A. (2018). Individual Response to Ionizing Radiation and Personalized Radiotherapy. Critical Reviews ${ }^{\mathrm{TM}}$ in Oncogenesis, 23 (1-2), 69-92. doi: http://doi.org/10.1615/critrevoncog.2018026308

4. Denham, J. W., Hauer-Jensen, M., Peters, L. J. (2001). Is it time for a new formalism to categorize normal tissue radiation injury? International Journal of Radiation Oncology Biology Physics, 50 (5), 1105-1106. doi: http://doi.org/10.1016/s03603016(01)01556-5

5. Wynn, T. (2008). Cellular and molecular mechanisms of fibrosis. The Journal of Pathology, 214 (2), 199-210. doi: http://doi.org/10.1002/path.2277

6. Hakenjos, M. Bamberg, H. P. Rodeman, L. (2000). TGF-beta1-mediated alterations of rat lung fibroblast differentiation resulting in the radiation-induced fibrotic phenotype. International Journal of Radiation Biology, 76 (4), 503-509. doi: http://doi.org/10.1080/095530000138501

7. Bentzen, S. M. (2006). Preventing or reducing late side effects of radiation therapy: radiobiology meets molecular pathology. Nature Reviews Cancer, 6 (9), 702-713. doi: http://doi.org/10.1038/nrc1950

8. Suit, H., Goldberg, S., Niemierko, A., Ancukiewicz, M., Hall, E., Goitein, M. et. al. (2007). Secondary Carcinogenesis in Patients Treated with Radiation: A Review of Data on Radiation-Induced Cancers in Human, Non-human Primate, Canine and Rodent Subjects. Radiation Research, 167(1), 12-42. doi: http://doi.org/10.1667/rr0527.1

9. Demina, E. A. (2016). Radiogennii rak: epidemiologiia i pervichnaia profilaktika. Kyiv: Naukova dumka, 196.

10. Vorobeva, N. Iu., Antonenko, A. V., Osipov, A. N. (2011). Osobennosti reaktsii limfotsitov krovi bolnykh rakom molochnoi zhelezy na obluchenie in vitro. Radiatsionnaia biologiia. Radioekologiia, 51 (4), 451-456.

11. Domina, E. A., Smolanka, I. I., Mikhailenko, V. M. (2018). Influence of the melanin-glucan complex on the radiosensitivity of cells of patients with premalignant pathology of breast. Reports of the National Academy of Sciences of Ukraine, 11, 84-90. doi: http://doi.org/10.15407/dopovidi2018.11.084

12. Kolusayin Ozar, M. O., Orta, T. (2005). The use of chromosome aberrations in predicting breast cancer risk. Journal of Experimental \& Clinical Cancer Research, 24 (2), 217-222.

13. Pelevina, I. I., Aleschenko, A. V., Antoschina, M. M. et. al. (2009). Povrezhdennost geneticheskogo apparata, induktsiia adaptivnogo otveta $\mathrm{v}$ limfotsitakh krovi pri rake predstatelnoi zhelezy. Sviaz s effektivnostiu luchevoi terapii opukholei. Radiatsionnaia biologiia. Radioekologiia, 49 (4), 419-424.

14. Gaziev, A., Shaikhaev, G.; Nenoi, M. (Ed.) (2012). Limited Repair of Critical DNA Damage in Cells Exposed to Low Dose Radiation. Current Topics in Ionizing Radiation Research. Vienna: Intech, 51-81. doi: http://doi.org/10.5772/33611

15. Tsishnatti, A. A., Rodneva, S. M., Smetanina, N. M. et. al. (2019). Thermo-radiosensitization of chemotherapy-resistant tumour cells. Radiobiological Basics of Radiation Therapy, International Conference. Dubna, 155-156.

16. Bhogal, N., Kaspler, P., Jalali, F., Hyrien, O., Chen, R., Hill, R. P., Bristow, R. G. (2010). Late Residual $\gamma$-H2AX Foci In Murine Skin are Dose Responsive and Predict RadiosensitivityIn Vivo. Radiation Research, 173 (1), 1-9. doi: http://doi.org/10.1667/rr1851.1 
17. Pelevina, I. I., Aleschenko, A. V., Antoschina, M. M. et. al. (2014). Sviazany li svoistva limfotsitov perifericheskoi krovi u bolnykh rakom predstatelnoi zhelezy s effektivnostiu luchevoi terapii? Radiatsionnaia biologiia. Radioekologiia, 54 (3), $273-282$. doi: http://doi.org/10.7868/s0869803114030126

18. Khvostunov, I. K., Kursova, L. V., Sevan'kaev, A. V., Ragulin, Y. A. et. al. (2019). The estimation of radiation effect to cancer patients treated with beam-therapy by means of analysis of chromosomal aberrations in blood lymphocytes. "Radiation and Risk" Bulletin of the National Radiation and Epidemiological Registry, 28 (2), 87-101. doi: http://doi.org/10.21870/0131-38782019-28-2-87-101

19. Cytogenetic dosimetry: applications in preparedness for and response to radiation emergencies. World Health Organization (2011). Vienna: IAEA, 247.

20. Domina, E. A., Chekhun, V. F. (2013). Experimental validation of prevention of the development of stochastic effects of low doses of ionizing radiation based on the analysis of human lymphocytes' chromosome aberrations. Experimental Oncology, $35(1), 65-68$.

21. Kliushin, D. A., Petunin, IU. I. (2008). Osnovy dokazatelnoi meditsiny. Kyiv: Dialektika, 320.

22. Domina, E. A. (2019). The dependence of dose/effects in human radiation cytogenetic. Problems of Radiation Medicine and Radiobiology, 24, 235-249. doi: http://doi.org/10.33145/2304-8336-2019-24-235-249

23. Lee, R., Yamada, S., Yamamoto, N., Miyamoto, T., Ando, K., Durante, M., Tsujii, H. (2004). Chromosomal Aberrations in Lymphocytes of Lung Cancer Patients Treated with Carbon Ions. Journal of Radiation Research, 45 (2), 195-199. doi: http://doi.org/10.1269/jrr.45.195

24. Senthamizhchelvan, S., Pant, G. S., Rath, G. K., Julka, P. K., Nair, O., Joshi, R. C. et. al. (2006). Biodosimetry using chromosome aberrations in human lymphocytes. Radiation Protection Dosimetry, 123 (2), 241-245. doi: http://doi.org/10.1093/rpd/ncl109

25. Roch-Levre, S., Pouzoulet, F., Giraudet, A. L., Voisin, Pa., Vaurijoux, A., Gruel, G. et. al. (2010). Cytogenetic assessment of heterogeneous radiation doses in cancer patients treated with fractionated radiotherapy. British Journal Radiology, 83 (993), 759-766. doi: http://doi.org/10.1259/bjr/210225597

26. Domina, E. (2020). Expediency on radiomitigators in radiation therapy of cancer patients. Journal of Science. Lyon, $1(10), 7-11$.

27. Domina E. (2020).The specificities of radiation carcinogenesis. Journal of Science. Lyon, 1 (11), 8-12.

Received date 22.12.2020

Accepted date 16.02.2021

Published date 31.03.2021

Emiliia Domina, Doctor of Biological Sciences, Professor, Head of Department, Department of Biological Effects of Ionizing and Non-Ionizing Radiation, R. E. Kavetsky Institute of Experimental pathology, Oncology and Radiobiology of National Academy of Sciences of Ukraine, Vasilkivska str., 45, Ukraine, Kyiv, 03022

E-mail: edjomina@ukr.net

Olha Hrinchenko, Postgraduate Student, Department of Biological Effects of Ionizing and Non-Ionizing Radiation, R. E. Kavetsky Institute of Experimental pathology, Oncology and Radiobiology of National Academy of Sciences of Ukraine, Vasilkivska str., 45, Ukraine, Kyiv, 03022

E-mail: griniolia@gmail.com 